NBER WORKING PAPER SERIES

\title{
TEMPORARY COLOCATION AND COLLABORATIVE DISCOVERY: WHO CONFERS AT CONFERENCES
}

\author{
Sen Chai \\ Richard B. Freeman \\ Working Paper 25993 \\ http://www.nber.org/papers/w25993 \\ NATIONAL BUREAU OF ECONOMIC RESEARCH \\ 1050 Massachusetts Avenue \\ Cambridge, MA 02138 \\ June 2019
}

We would like to thank the Chemical Heritage Foundation's Beckman Library for the travel grant to access the Gordon Research Conferences' attendance data and the Research Program on the Economics of Knowledge Contribution and Distribution, funded by the Sloan Foundation, for supporting this work. We are appreciative of the comments we received from Sujin Jang, Matthew Lee, Anoop Menon, Matthew Marx, Anca Metiu, Valery Yakubovich, Anil Doshi, and Luciana Silvestri, participants of the REER 2013 conference and the 2014 HBS TOM Alumni Workshop. We are also grateful to Marissa Suchyta and Sifan Zhou for their research assistance. All errors remain our own. The views expressed herein are those of the authors and do not necessarily reflect the views of the National Bureau of Economic Research.

NBER working papers are circulated for discussion and comment purposes. They have not been peer-reviewed or been subject to the review by the NBER Board of Directors that accompanies official NBER publications.

(C) 2019 by Sen Chai and Richard B. Freeman. All rights reserved. Short sections of text, not to exceed two paragraphs, may be quoted without explicit permission provided that full credit, including $(\odot$ notice, is given to the source. 
Temporary Colocation and Collaborative Discovery: Who Confers at Conferences

Sen Chai and Richard B. Freeman

NBER Working Paper No. 25993

June 2019

JEL No. O0,O3,O31,O33,O34

\begin{abstract}
$\underline{\text { ABSTRACT }}$
The flow of knowledge is closely linked to proximity. While extensive works show that longterm geographic proximity affects work behavior, little is known about the effect of short-term collocation, such as conferences. Using participant data at Gordon Research Conferences, we estimate difference-in-differences and instrumental variable models, which show that attendees who have no prior within-conference collaborations are more likely to collaborate with other attendees, and that the researchers who have worked previously with other attendees are more likely to continue their collaborations. We also find that researchers who are junior, are located closer to the conference venue, and have established prior ties to the conference draw more collaborative benefits from temporary collocation across organizations. Thus, going to a conference alters the creation of collaborations.
\end{abstract}

\author{
Sen Chai \\ ESSEC Business School \\ Cergy-Pontoise \\ France \\ chais@nber.org \\ Richard B. Freeman \\ NBER \\ 1050 Massachusetts Avenue \\ Cambridge, MA 02138 \\ freeman@nber.org
}




\section{INTRODUCTION}

Geographic proximity has been shown to reduce the costs of meeting and interacting with others, and therefore to enhance the flow of information and the formation of collaborative ties. This has been found to be true in various research traditions and levels of analysis. Regional studies on agglomeration find substantial knowledge transfer among firms located near one another (Jaffe et al., 1993; Thompson et al., 2005), as well as between firms and nearby universities (Anselin et al., 1997; Jaffe, 1989; Sohn, 2017). Management chooses firm location in part to tap into the knowledge stock from clusters of regional spillover (Alcacer et al., 2007; Chung et al., 2002). Within firms, information diffuses better than across firms because organizational boundaries act as a physical barrier that hinders the transmission of ideas between them (Kogut et al., 1992). Consequently, setups such as headquarters (Kleinbaum et al., 2014), company towns (Agrawal et al., 2010), and corporate campuses (Becker et al., 2003) facilitate contact and interactions between organizational members. At the micro level, within buildings, the layout of offices (Allen, 1977; Oldham et al., 1979) and laboratories (Catalini, 2017) can influence the level of interaction among members. Hence, managers face important decisions with long-term strategic ramifications (Ghemawat, 1991) regarding where to locate firms, plants, and R\&D centers, as well as how to lay out workspaces inside the firm to enhance knowledge spillover and collaboration.

Permanent proximity, however, may be difficult and sometimes impossible to attain due to loss of productivity and prohibitive costs associated with moving, as well as the lack of available space. One potentially important way of overcoming the distance disadvantage in knowledge spillover and tie formation is through temporary colocation events that bring together individuals from distant locations in an environment of temporary proximity. Examples of temporary colocation events abound. Within firms, mixers (Ingram et al., 2007), informal 
activities (Liu et al., 2015), site visits, and rotational programs are organized to allow colleagues from different locations to become familiar with one another (Hinds et al., 2013). Locate a lunchroom (Sommer, 1959), a photocopier (Fayard et al., 2007), or other forums (Chown et al., 2015) between two work groups, and the interactions that ensue may lead to information spread and collaborative projects stemming from ad hoc exchanges around the proverbial water cooler. Similarly, in academic institutions, research events (Boudreau et al., 2017) and semiformal structures that meet temporarily (Biancani et al., 2014) also facilitate interactions and collaborations.

However, most of this research on temporary colocation has been limited to studying individuals in the same organization located within a small physical radius. Although examples of temporary colocation outside organizational boundaries abound, such as participation in trade shows, conferences, and technical committees, only a few papers have studied them. They have alluded to the importance of after-work activities in enhancing information exchange and the vibrancy of a region (Saxenian, 1994) and have found increases in alliance formation when firms sit in on common technical committees (Rosenkopf et al., 2001). Hence, temporary colocation across organizations can be a crucial source of knowledge diffusion and collaboration for firms seeking to build their absorptive capacity (Cohen et al., 1990) and set up alliance networks (Gulati, 1998). However, the literature on knowledge spillover has mostly assumed passive contact from close proximity without delving into the effect of specific setups of temporary colocation across organizations. Exploring these effects as a potential alternative to overcoming the distance disadvantage to spillover and collaboration is crucial, especially given that organizational boundaries and shorter timeframes limit interactions and may not translate as easily into tie formation. 
Hence, we contribute to the literature by going beyond organizational boundaries and isolating the effect of temporary colocation. We use the setting of conferences as a useful empirical window to study temporary colocation across organizations because attendees come from different academic institutions; participation is easy to track, thanks to the availability of attendance lists; and the subsequent ties formed are encoded in peer-reviewed publications. Specifically, we ask and address three research questions: who is most likely to attend conferences, how temporarily colocating across organizations at conferences affects subsequent collaborative behaviors, and how it benefits different types of attendees differently. Thus, we are able to trace the real consequences of temporary colocation across organizations over time, as measured by participants' distant collaborative tie formations (Sorenson et al., 2008), in a way that prior studies have failed to do or overlooked.

The empirical challenge of linking temporary colocation at conferences to distant tie formation is the endogeneity of scientists' decision to attend a conference. In other words, estimating what attendees' collaborative behavior might have been had they not attended the conference, and disentangling the effects of selecting oneself into a conference and the actual treatment effect of participating is particularly difficult. To address these issues stemming from omitted variable bias, we compare the difference in collaborations before and after conference attendance and the difference between attendees and a constructed control group of researchers using a difference-in-differences setup (DiD), while exploiting exogenous variation in distance to the conference (Fleming et al., 2007), career stage, and similarity to the average conference attendee as instrumental variables to predict for attendance. Finally, the empirical burden is lessened when we explore the heterogeneous effects of temporarily colocating at conferences, as they are conditional on attendance. 
Our results show that collaborations between attendees increased by $9.4 \%$ for those with no prior publication ties within the conference. The subset of attendees with preexisting withinconference collaborations were more likely to attend to meet prior collaborators, and subsequent within-conference collaborations increase by 19.5\%. We also find that although older researchers are more likely to participate, they benefit less than juniors from forming collaborations.

Moreover, researchers located closer to the conference are not only more likely to attend, but also tend to form more subsequent collaborative ties and to be influenced by the conference. Finally, having prior collaborative ties boosts subsequent collaborative ties. Overall, these results imply that even when researchers from different institutions are proximate for a short period of time, they can reap knowledge spillover and collaborative benefits.

\section{TEMPORARY COLOCATION ACROSS ORGANIZATIONS AND COLLABORATIVE DISCOVERY}

Temporary proximity across organizational boundaries provides a short window for interaction between distant individuals who otherwise likely would not have had the chance to interact. These occasions, such as our setting of conferences, provide a physically and temporally condensed forum for participants from different institutions to come together. These conferences are a subset of temporary colocation events across organizational boundaries, where attendees can share work through posters and presentations, exchange information during breaks, and otherwise build intellectual links.

Our focus on studying collaborative ties stems from its importance in the creative process, which ultimately leads to economic growth for firms and society (Mansfield, 1972; Rosenberg, 1974). In a world of expanding knowledge, where research problems require diverse expertise (Basalla, 1988; Grandori, 2009), teams have become the main producer of knowledge 
in all scientific and technological domains (Wuchty et al., 2007). This makes the search for collaborators critical in scientific work and careers. Individuals in a team pool expertise (Jones, 2009), use ideas from others creatively (Fleming, 2001), and weed out bad ideas (Singh et al., 2010). Breakthrough advances rely on the novel recombination of ideas/knowledge from diverse sources (Hargadon et al., 1997), which is enhanced by collaborative work.

The mechanism of collaborative tie formation can be conceptualized as a matching process where geographic proximity reduces the effort and cost needed to search for and find related research and potential collaborators and work with them efficiently (Fafchamps et al., 2010). Regular contact among researchers in a department, university, or city eases the path to a common topic of interest for collaborative work (Fleming, 2001). Irregular contact across institutions at conferences offers participants a venue that fosters a sense of community, provides social proximity (Feld, 1981), and enables the exchange of ideas through face-to-face meetings that substitute mobility (Almeida et al., 1999) and temporary colocation for longer-term proximity (Katz, 1994). Overall, temporary colocation across organizations lowers the cost of information search available beyond the boundaries of the organization and provides an environment conducive for collaborations, as its condensed format enables a relatively large amount of useful information to be exchanged. Video chat and Internet-based communication (Agrawal et al., 2008) notwithstanding, face-to-face meetings can help reassure participants that the benefits of collaboration outweigh the costs of coordination (McFadyen et al., 2004).

Temporary proximity at conferences reduces the cost of exchanging knowledge for dissemination (Tham, 2018) and subsequent usage, as attendees not only seek but also contribute information through presentations and posters. Being able to question a presenter on unclear points or test one's interpretation of procedures or outcomes in informal discussion can lead to better transfer of tacit knowledge as compared to simply reading a published journal article. 
Questions or comments may also stimulate thinking in ways that would not happen from reading the literature. The result should be more efficient knowledge transfer and the combination of ideas in different contexts (Fleming, 2001) that presumably appear in subsequent publications.

Although participants stand to benefit collaboratively from attending temporary colocation events across organizations, participants are heterogeneous. As in the case of firms, agglomeration economies potentially provide spillover benefits, but since firms are also heterogeneous, not all firms will seek to agglomerate (Shaver et al., 2000), as not all will reap the same benefits. Similarly, not all researchers will choose to temporarily colocate; doing so is a strategic choice that researchers make presumably to maximize research output, since each individual is likely to benefit differently. However, those who are more likely to colocate are not necessarily those who benefit the most. Hence, in our setting of temporarily colocation across organizations at conferences, we investigate whether prior ties (Fayard et al., 2007; Festinger et al., 1950; Zipf, 1949), career stage, similarity to the average conference attendee (Feld, 1981; Ruef et al., 2003; Stuart et al., 1996), and distance to the conference (Coleman, 1988; Obstfeld, 2005; Uzzi, 1997) are likely to influence attendees differently.

Even before attending a conference, some participants may have already worked together or at least know of one another's work. Increased interactions at conferences strengthen bonds and enhance information flow, thereby further lowering search costs and boosting tie formation (Fayard et al., 2007; Festinger et al., 1950; Zipf, 1949). Hence, prior collaborative and citation ties, especially among those attending the same conference, are likely to positively affect future collaborations.

Attending a conference is likely to affect scientists differently at different stages of their careers. We expect junior researchers who are young and relatively unknown to benefit more 
from conferences than senior ones. A conference that allows junior researchers to showcase their interests and ability, and that introduces them to work they might not have known, could spur collaborations by lowering the information search costs involved in finding such junior participants. Due to their larger networks and knowledge of others' work, senior researchers may have less need to create connections and reveal information about themselves at a conference.

Closeness in technical space (Stuart et al., 1996), research focus (Feld, 1981; Ruef et al., 2003), and personal characteristics (Freeman et al., 2015; Kleinbaum et al., 2013; McPherson et al., 2001) may affect the composition of attendees and the effects of the conference on attendees. Participants with a research profile closely related to the conference's theme, with comparable ages and productivity, may interact more and share more common interests than others, thereby lowering search costs and facilitating new collaborations and the dissemination of ideas. ${ }^{1}$

The geographic location of researchers relative to the conference venue may also affect who attends a conference and what they gain from it. Attending a conference close by enables participants to establish a network centered on the conference, and being in this central position facilitates the flow of information and resources (Coleman, 1988; Obstfeld, 2005; Uzzi, 1997). Participants located near the conference may help with its organization and thus connect more with other participants. ${ }^{2}$ Other attendees may also be more likely to seek out participants located close to the conference location and extend their stay for work sessions. All these increased interactions lower search costs.

In short, we posit that attending a conference increases the number of future collaborations with other attendees and impacts the inventive direction of subsequent

\footnotetext{
${ }^{1}$ These effects also hold for geographically and technologically proximate firms that gain knowledge from each other for innovation (Audretsch et al., 2004; Breschi et al., 2001; Feldman et al., 2010).

2 Certain conferences, such as SMS, designate program chairs from universities located near the location.
} 
publications, with magnitudes that differ among those in different career situations and pre-event connections to attendees.

\section{METHODOLOGY}

\section{Setting: Gordon Research Conferences}

We study temporary proximity in the context of the Gordon Research Conferences (GRC). GRC is one of the major conference series in the natural sciences; currently, over 200 GRCs are organized in the biological, chemical, and physical sciences and related technologies each year. GRCs are relatively small, specialized conferences organized in a decentralized manner by groups of scientists who are experts in the area of the conference. To participate in a GRC, attendees must apply by submitting an abstract and be accepted through a peer-review process by researchers on the organizing committee. The number of participants is usually between 80 and 150, where for one week attendees come together at remote sites. GRCs cost about U.S.\$1,000, which includes meals and housing for the full week in campus dorms. Travel grants are available if the author of an accepted work lacks sufficient funds to participate.

Each GRC conference is organized around a single overarching topic. Hence, the advantage of studying GRCs is that, as compared to bigger conferences, where attendance is difficult to track, GRCs list the attendees present. GRCs are single-track conferences without any parallel sessions, which aids in building a community. Informal afternoon activities are also scheduled into the conference to ensure more face-to-face interactions. Moreover, academic conferences provide a setting where subsequent spillover and collaborative tie formations are more easily measured using publication productivity. 


\section{Data and Empirical Strategy}

To address our three research questions of who is more likely to attend conferences, how temporarily colocating at conferences affects subsequent collaborative behaviors, and how it benefits attendees differently, two sets of data are required: (1) lists of conference participants and (2) publication data on participants's scientific output. We hand-collected and digitized attendance lists for 15 biological $^{3}$ GRCs between 1992 and 1995 from the Chemical Heritage Foundation's Beckman Library and manually matched 1,254 unique attendees ${ }^{4}$ onto the Authority database (Torvik et al., 2009). Table 1 describes each conference, including topic, year held, and location.

\section{[Insert Table 1 about here]}

In the baseline of linking temporary colocation effects at conferences to collaboration, the empirical challenge is to address three endogeneity issues which clouds causal interpretation: (1) the conference committee accepting submissions of more productive researchers, (2) estimating what attendees' collaborative behavior might have been had they not attended the conference, and (3) the decision of researchers to seek to attend a conference. ${ }^{5}$

For counterfactual comparison, we matched attendees with a sample of researchers who did not attend the conference using the MedLine bibliometric data. This database covers all researchers whose work appears in Medline, or about nine million researchers, including all of

\footnotetext{
${ }^{3}$ We chose GRCs in biology because we have access to the disambiguated Author-ity database of all Medline publications in the life sciences needed to obtain peer-reviewed publication data.

${ }^{4}$ Out of these 1,254 unique attendees, 10 individuals attended more than one GRC conference in our sample.

${ }^{5}$ Our initial research design was to compare individuals who were accepted but did not attend versus those who did. Unfortunately, due to data availability constraints stemming from privacy concerns of the event manager, we could not implement this design.
} 
our GRC attendees. We first matched the top three Medical Subject Heading (MeSH) keywords ${ }^{6}$ from attendees and non-attendees' five-year prior publications. If the set of potential matched non-attendees by research focus is greater than one, we refined the matching by finding the neighbors nearest to each attendee based on years of experience since first publication, the number of five-year prior publications, collaborations, and forward citations received. Weighing all four dimensions equally, we kept the two nearest neighbors with the shortest Euclidian distance to the attendee being matched and identify for each attendee one to two closest researchers who did not attend the conference with a sample totaling 2,016 individuals. Since our matching specification is based first and foremost on research focus similarity, this procedure allows us to compare scientists with similar research interests who differ in their participation.

If the matched sample truly includes individuals most analogous to attendees, there should be no significant difference on the observable dimensions in the five years prior to the conference. Two-sided t-tests on these dimensions in Table 2 confirm that both groups were not significantly different. Matching by the average values of characteristics, however, does not necessarily establish a good control group. It leaves open the possibility that individuals with similar levels of variables could differ in changes in variables, which risks erroneously attributing a post-event trend to the event rather than to a prior trend. Accordingly, we compared year-by-year trends of the matched group and of attendees before the attendees' Gordon Conference. Figure 1 shows that trend changes in number of publications, collaborations, and forward citations are similar between the attendees and the matched group of non-attendees.

[Insert Figure $1 \&$ Table 2 about here]

\footnotetext{
${ }^{6} \mathrm{MeSH}$ keywords are assigned to each article to describe the topics covered in the article. Since these controlled keywords are not assigned by the authors but by an independent indexer, they are viewed as a relatively objective classification scheme. Indexers are from the National Library of Medicine of the NIH.
} 
Given that Gordon Conferences invite researchers interested in similar topics, some attendees invariably worked together in the past, which increases their likelihood of future collaborations independent of conference attendance. We deal with this issue by analyzing separately the behavior of participants with and without prior collaborative links.

Comparing attendees and non-attendees on many observable dimensions arguably increases the plausibility of a causal interpretation of before/after differences but still leaves open the possibility that some unobservable difference between the two groups accounts for differences in behavior ex ante even prior to the treatment. Specifically, net of observables, scientists could have attended the conference because they were actively seeking new collaborations or had a greater underlying tendency to do collaborative work. Such differences are not captured by the observable variables. Using a two-stage least squares setup, we include drivers of selection as instruments to determine conference attendance in the first stage.

One potential driver of attendance is career stage, as researchers in certain periods of their careers may be more likely to make the strategic choice of attending to maximize their research output. The similarity of a researcher's research profile to the conference average also dictates the likelihood of and purpose of attending. Attendance by similar participants is more likely to be random, as they can just as easily choose other events to engage in with their community, while less-similar participants are more likely to attend for a particular reason. Another driver of selection is distance (Fleming et al., 2007), as some attendees may be located close to the conferences they attend while others travel much greater distances to attend. The distance of travel in our sample ranged from 30 to over 10,000 miles. People are less likely to attend a conference when they are located far from its venue due to the inconveniences of travel.

When exploring the research question of who benefits more from temporary location, the empirical burden is lessened considerably, as we focused on variations between attendees. 
Because these effects are conditional on participation, our empirical strategy centered only on attendees and their behavior after the conference event.

\section{Variables}

The data is an individual-year panel with annual observations for five years before and after conference attendance. Table 3 shows the description and summary statistics, including sample size, mean, standard deviation, and minimum and maximum of each variable. Table A1 in the Appendix respectively show the correlation matrix for the full and conditional on attendance samples. The key dependent variables are all based on publications.

[Insert Table 3 about here]

Collaborative ties. We developed two variables to explore the collaborative tie formation of attending a conference. We first counted the overall number of papers on which researchers collaborated with one or multiple coauthors, irrespective of where they met the collaborators (collaborations). We then focused on collaborations formed between conference participants (collaborations between attendees), which has the number of attended-attended collaborations for the attendee group. Because the counterfactual sample consists of would-be participants in the same scientific domain, we took the number of collaborative links formed between the would-be attendees and participants of the conference.

Inventive direction of output. Conditional on participation, we quantified the extent to which works of participants drew from knowledge embedded in the conference itself. We counted the number of MeSH keywords subsequent publications of attendees have in common with the conference's top 10 percent most frequent keywords (common MeSH). We defined the core knowledge space of the conference to be the aggregate knowledge of all attendees by using their five-year prior publications’ MeSH terms as proxy. 
Attended, post, and post $x$ attended interaction. To setup the difference-in-differences (DiD) model, we employed three indicator variables: attended equals one indicates that an individual attended a GRC conference; post equals one indicates that the data point is after the conference, irrespective of whether the individual attended a GRC conference or not; and post $x$ attended equals one, the interaction of attended and post, indicates that the data point is after the conference and that the individual attended a GRC conference. We also included an indicator variable (multiple attendance) for individuals who attended more than one GRC in our sample.

Prior collaborative and citations ties. When studying variation in effect for attendees, we accounted for the number of collaborations (prior collaborations) and citations (prior citations) between attendees in the five-year pre-conference period.

Career stage. Experience is the number of years since a researcher's first publication until the year of the conference. We also included an indicator variable for junior researchers (junior) equal to one if the researcher had ten years or less of experience. We used ten years as an approximation for time to tenure from first publication, assuming researchers first publish in the late stages of their doctorate and take an average of seven to eight years to tenure once in a faculty position. We also used seven years and 12 years of experience from first publication as cutoffs for robustness tests.

Similarity of research profile. We sorted attendees on how similar they are to the average characteristics of all conference attendees. We defined the conference average characteristics based on six dimensions derived from the five-year prior publications of all attendees: average number of an individual's MeSH terms that matches the conference's top 10\% most frequent MeSH terms, average number of publications, average number of collaborations, average number of collaborators, average number of forward citations, and average experience at the time of the conference. We considered an attendee to be similar to the conference average for a 
particular dimension if the individual value falls within the middle $50 \%$ of the sample distribution, and counted the number of similar dimensions.

Distance. We calculated the distance to conference in miles from the researcher's primary affiliation at the time of the conference to the meeting venue. Furthermore, for each publication, we calculated the average distance between all collaborators on the same publication (average collaborative distance).

Publication and citation. We also controlled for the quantity of knowledge produced by each individual using the number of peer-reviewed publications per year and their garnered citations in the five-year period after its publication.

\section{Model Estimation}

To the extent that attendance at a conference varies with measurable attributes of scientists, we include a wide variety of covariate controls in our calculation. This should help identify the effects of attendance per se on outcomes, but even a large set of observables leaves open the possibility that some unmeasured attribute lies behind attendee and non-attendee differences in outcomes that would make the conference more of a pathway than an exogenous cause of outcomes. To estimate of the impact of treatment, we develop instrumental variable models that replace conference attendance with a predicted attendance measure.

The econometric structure for our empirical model is a before/after panel around an attendance event. We exploit the panel data by including fixed effects for individuals in most calculations so that estimated coefficients reflect responses to independent variables by the same person over time and include conference fixed effects so that results are for the same person at a given conference. The DiD model captures the difference between the change in the dependent 
variable for attendees versus non-attendees and removes potential bias in post-period comparisons due to permanent differences and prior trends between attendees and non-attendees:

$$
Y_{i, s, t}=\alpha+\lambda \text { post }_{i, t}+\beta\left(\text { post }_{i, t} \cdot \text { attended }_{i, s}\right)+\delta X_{i, t}+\varepsilon_{i, s, t}
$$

But attendance depends on a researcher seeking to attend and the organizing committee accepting them, and thus does not allow for a simple random variation causal interpretation of attendance on outcomes. To deal with endogenous attendance, we instrument attendance on researcher experience, distance to conference, and similar dimensions to a conference in a first stage equation:

$$
\text { attended }_{i, s}=\text { distance }_{i, s}+\text { experience }_{i, s}+\text { similar dimensions }_{i, s}+\delta X_{i}+\varepsilon_{i, s}
$$

The second-stage estimating equation regresses predicted attendance from equation (2) onto the output, given by:

$$
Y_{i, s, t}=\alpha+\lambda \text { post }_{i, t}+\beta\left(\text { post }_{l, t} \cdot \text { attended }_{l, s}\right)+\delta X_{i, t}+\varepsilon_{i, s, t}
$$

The outcome variable is $Y_{i, s, t}$ for researcher $i$ at time $t$ for attended state $s$. Conference attendees are exposed to the treatment of attending the GRC conference in the post period, while the group of non-attendees is not exposed to the treatment in the pre- or post-periods. Attended is the indicator of whether individual $i$ has attended a conference at time $t_{0}$, but since we used individual fixed effects in our regression specifications, the term drops out from equations (1) and (3). Post is the indicator of the period after conference, and $\lambda$ is the difference between the pre- and post-conference periods, irrespective of the group. The $\mathrm{DiD}$ is captured by the interaction of attended $_{i, s}$ and post $_{i, t}$, where $\beta$ is the coefficient of interest. For each individual $i$ in the vector $X_{i, t}$, we included covariates for observables, such as yearly individual characteristics like the number of publications and citations.

For attendees who never collaborated within the conference, the model simplifies to a 
post period panel model, where $\gamma$, the coefficient for the attended indicator, is that of interest ${ }^{7}$

$$
Y_{i, s, t}=\alpha+\text { rattended }_{i, s}+\delta X_{i, t}+\varepsilon_{i, s, t}
$$

Instrumenting for attendance, we use equation (2) to estimate the first stage; and the second stage equation regresses output on predicted attendance from equation (2),

$$
Y_{i, s, t}=\alpha+\gamma \text { att } \widehat{\text { ende }} d_{l, s}+\delta X_{i, t}+\varepsilon_{i, s, t}
$$

The empirical model for variations between attendees does not require the DiD nor instrumental variable setups; hence, it simplifies from equation (1) to

$$
Y_{i, t}=\alpha+\beta \text { variation of } \text { interest }_{i}+\delta X_{i, t}+\varepsilon_{i, t}
$$

Because variations between attendees are conditional on attendance, the outcome variable becomes $Y_{i, t}$ for attendee $i$ at time $t$. The coefficient of interest is $\beta$ for attendee $i$ 's variation of interest at the time of the conference. We included covariates for observables $X_{i, t}$, such as conference fixed effects, as well as yearly individual characteristics, such as the number of publications and citations.

Finally, since the outcome variables in equations (3) and (5) are non-negative and overdispersed counts, we took the natural logarithm of the dependent variables plus one and ran OLS models to minimize estimation bias. For equation (6), we ran quasi-maximum likelihood Poisson models. We took the natural logarithm plus one for count variables whenever they entered the regression on the right-hand side to match count explanatory variables that underwent the same transformation on the left-hand side.

\footnotetext{
${ }^{7}$ Due to collinearity between individual fixed effect and the variable of interest attended, we dropped the former.
} 


\section{RESULTS}

Figure 2 shows the basic pattern in the data on collaborations that underlies our analysis. Panel A illustrates the overall between-attendee raw collaboration patterns and can be decomposed into panels B and C. Panel B reveals a subtle before/after pattern of change for attendees who had collaborated with other attendees before their GRC conference. It shows little difference in the pattern of collaborations between attendees and matched non-attendees in the first three years of the sample period, followed by an increase in collaborations for attendees over the next three years that produces an attendee/non-attendee gap that diminishes as collaborations decline for both groups thereafter. Determining the effect of GRC attendance is complicated by both the life cycle of collaborations and the potential endogeneity of going to a conference to strengthen or maintain a collaboration. Panel C displays the average number of collaborations between attendees for researchers who had never written with anyone else at the conference before attending. They are the group for whom we would most expect to see collaborations develop. Indeed, the number of collaborations jumps from zero before attending a GRC to an average number of 0.2 collaborative works after attendance, indicating that roughly one-fifth of these attendees ended up collaborating with others.

[Insert Figure 2 \& Table 4 about here]

We use the econometric model developed in equations (2) to (5) to determine whether these graphical results and interpretations hold up to more detailed statistical probing and assess the magnitude of the before/after patterns. The estimates for attendance in the first stage of the first two models in Table 4 show that attendees located closer are more likely to participate; they are also older, and their research profiles are more similar to the conference average. The Fstatistic is well above the threshold of 10 for strong instruments. 
Turning to the estimated effect of attendance on outcomes in the second stage, we first establish a baseline for the change in overall collaborations of researchers (Model 1). We find a modest but insignificant increase of $2.1 \%{ }^{8}$ in overall collaborations for attendees as compared to non-attendees after the conference. Reassuringly, the effect on overall collaboration is small and insignificant, as we do not expect attendees’ overall collaborative behavior to change drastically after being temporally proximate. Instead, who attendees collaborate with matters more.

The estimated effect of attendance on collaborations between attendees decreases insignificantly by 1.8\% (Model 2). To tease out the confounding effect of existing collaborators attending conferences together, we further decomposed the sample into researchers who had prior collaborations within the conference (Model 3) and those who had never collaborated with anyone attending the conference (Model 4). ${ }^{9}$

The propensity to attend conferences from the first-stage estimation also changes with this sample decomposition. Participants traveling less and with more experience are still significantly more likely to attend. However, those with prior existing collaborations (Model 3) differ more from the conference average. These results imply that those with existing collaborations are more likely to attend in order to meet standing collaborators, whereas those without existing collaborations with conference attendees (Model 4) are attracted to the conference by its theme and topic.

In the second stage, between-attendee collaborations are significantly higher by $19.5 \%$ for conference attendees with prior collaborations within the conference. The calculations for

\footnotetext{
${ }^{8}$ Effect size $=\mathrm{e}^{\text {coefficient }}-1=\mathrm{e}^{0.0204}-1=0.0206=2.06 \%$

${ }^{9}$ Since Model 4 focuses on the subsample of collaborations from attendees without any existing collaborations within the conference, all pre-conference values of the dependent variable are zero. Hence, we drop these preconference observations. This explains why the number of observations in Models 3 and 4 do not add up to the number of observations in the full sample used in Models 1 and 2.
} 
attendees without any prior within-conference collaborations show that attending the conference increases within-conference collaborations significantly by $9.4 \%$. The estimated effect of attendance for the subset of attendees with prior within-conference collaborations is higher than for those without collaborations, again showing that the former is more likely to attend to meet existing collaborators. These instrumental variable estimates show a smaller impact than uninstrumented DiD regressions ${ }^{10}$ (see Table A5 in Appendix), presumably due to the endogeneity of selection, as individuals with no previous collaborations attend in part to obtain new collaborators. Given that collaborative ties require involvement and commitment and can be costly to maintain, these magnitudes in effect sizes are expected.

The average collaborative distance between conference collaborators is greater for collaborations between attendees than for those between attendees and matched non-attendees, per Figure 1D. This implies that the collaborations are mainly distant ties and that the increase in collaborations among attendees is not driven by researchers from the same institution, or institutions located in close proximity, coming back to work together.

\section{Additional Evidence from Attendees}

Another way of probing the linkages in temporary colocation across organizational boundaries and collaboration is to take attendance at a conference as a given and to examine the variation in collaborations and research directions among attendees with different characteristics, such as prior ties, similarity in research profile, career stage, and distance to conference, as shown in Table 5. We controlled for the participant's yearly number of publications and forward citations for all regressions, and multiple conference attendance. Tables A2 and A3 in the

\footnotetext{
${ }^{10}$ For instance, Model 4 in Table A5 indicates very strongly and significantly that attending the conference increases collaborations with a fellow attendee by 10.5 times for the subset of attendees without any prior collaborations within the conference.
} 
Appendix respectively show incremental models using the two dependent variables. Effect directions are stable as more explanatory variables are added, while the log likelihood decreases, indicating gradual improvements in model fit.

As expected, existing collaborative ties between attendees prior to the temporary colocation event influence the formation of additional collaborative ties, as the conference provides an additional venue to deepen discussions and relationships (Model 1). We find that a one standard deviation increase in prior collaborative ties is associated with a $117.4 \%{ }^{11}$ positive and significant increase in new collaborations between attendees. A one standard deviation increase in prior citations ties, however, is associated with an $18.8 \%$ significant decrease in new collaborations. Prior citations indicate knowledge of one's work, but do not necessary translate into collaborations, especially given the number of references used in today's scientific work. Junior attendees benefit more from temporary colocation because information search costs are greatly lowered for them; they are associated with a $64.4 \%$ higher likelihood of forming collaborations with fellow attendees than seniors. Finally, given that conferences are a key resource for scholarship, being permanently close to the conference venue present advantages: a one standard deviation increase in a participant's permanent distance to the conference is associated with a 9.1\% significant decrease in forming a collaboration with other attendees.

When exploring the inventive direction of between attendee collaborative outputs (Model 2), we discover slightly different results. We find that prior collaborations and career stage have insignificant effects on the number of common MeSH keywords. However, a one standard deviation increase in prior citations is associated with a $10.3 \%$ positive and significant increase in common MeSHs. Attending a conference may remind participants of their prior knowledge of

${ }^{11}$ Effect size $=\frac{e^{\beta_{i} \cdot\left(\mu_{i}+\sigma_{i}\right)}}{e^{\beta_{i} \cdot\left(\mu_{i}\right)}}-1=\frac{e^{0.833 \cdot(0.759+0.932)}}{e^{0.833 \cdot(0.759)}}-1=1.174$ 
certain works and increase their subsequent use. Similarly, participants with profiles who are one standard deviation more similar to the conference average are $8.4 \%$ significantly more likely to produce subsequent works that match the theme of conference. Finally, inventive direction tends to be slightly more centered around the conference location, as a one standard deviation increase in a participant's permanent distance to the conference is associated with a $2.4 \%$ significant decrease in common MeSHs.

[Insert Table 5 about here]

\section{Views of Participants}

Finally, to get another perspective on what scientists get from going to conferences, we interviewed 18 life scientists with similar profiles to those in our sample. We asked open-ended questions with no reference to any of our findings. Representative responses, given below, provide our quantitative analysis with a richer, more sophisticated view of what scientists perceive to be the gains of going to conferences. These views are broadly supportive of our interpretation of our results. The actions described show temporary colocation across organizations as a forum for participants to brainstorm, interpret results, and develop together, and thus act as platforms that influence subsequent inventive direction. The quotes also illustrate how participants gather information and update their information sets when temporarily colocating at conferences, which is an essential step in potentially establishing collaborative links with other attendees.

Attendees are influenced by the sessions they attend, as the following quotes illustrate:

"[Conferences] provide a pretty easy way of keeping up to date with the field, staying current, [be]cause it's easier to sit back and hear a series of talks. [...] You are finding out information that's usually unpublished, than to wait and find that information in journals.”- molecular geneticist, Canada 
“And it only requires you going along to one conference. We've been clearly influenced. We had a theory, we didn't have any confidence in it, and this guy from Harvard shows up and talked about something utterly different, and you think that's worth doing a few experiments." molecular biologist, United Kingdom

Moreover, attendees also reap networking benefits from conferences outside of the formal sessions, as illustrated below:

"The most important thing at conferences is what you hear in the halls and in the coffee breaks. For example, we heard about microRNAs way in advance before there were publications, in a train station on our way to a conference.” - epigeneticist, France

"Both of you will hear a talk. You can discuss what you think are the reasons, what's really happening there, to what extent you think it's going to be reproducible, to what extent is this really going to change the way people think, are there other explanations. All these things you can do between sessions, and also talk to people about some surprising thing that you're finding and get input and be able to test ideas with.” - biologist, United States

\section{Robustness Tests}

We undertook a variety of robustness tests of our empirical results to see the extent to which somewhat different specifications might have yielded different results. For conciseness, some regression tables are not shown herein but are available from the corresponding author.

Citations. Collaborative ties encompass both knowledge spillover and knowledge cocreation. In our main effects, we focus on collaborative ties because they represent increased levels of commitment in tie formation, as the co-creation of knowledge requires more involvement and interactions among coauthors. We also performed our analysis using spillover ties as measured by the usage and recognition of ideas from various sources using citation patterns. Using the same regression setup and models as for collaborative ties, we find that attending the conference significantly increases citations by new citers by 28.4\% (Model 3 Table A4) for the subset of attendees who had not previously been cited by anyone at the conference.

Collaborations vs. collaborators. Since the distribution of how frequently researchers collaborate with one another may not necessarily be uniform — that is, some researchers may collaborate with the same individual multiple times, while others may have a broader set of 
infrequent collaborators — we performed the same set of analyses on unique collaborators instead of on collaborations. A high correlation between collaborations and collaborators (0.8787) indicates that the results are fairly analogous.

Matched-matched counterfactual sample. In the analysis of between-attendee collaborations, we used the counterfactual group of attended-matched links to compare to attended-attended links. A second plausible comparison measure is the link formed between matched would-be participants themselves-in other words, matched-matched links. Comparing regression coefficients, we find that collaborations between attended-attended are greater than

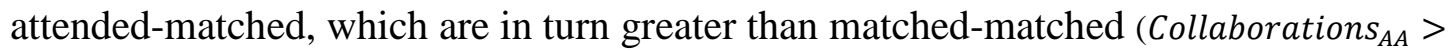
Collaborations $_{A M}>$ Collaborations $_{M M}$ ). Hence, the effect sizes shown in our main findings are more conservative. These findings suggest that collaborative ties in the matched-matched counterfactual group are even less likely than between the attended-matched group and can be explained by how matched researchers were determined. Since we matched each participant individually, the matched researchers are closer in knowledge space and other observables to attendees than between themselves.

Other definitions of junior attendee. We included two other definitions for junior attendees—-seven and 12 years from first publication to tenure-and find robust results to the 10year definition, where junior attendees benefit more than senior attendees for subsequent withinconference collaborations.

Plymouth indicator variable vs. Conference fixed effects. We also ran regressions using a Plymouth indicator variable without conference fixed effects (since six out of 15 conferences were held in Plymouth, NH), and found similar results to the shown models with conference fixed effects. However, since the Plymouth indicator variable is collinear with indicators for the conference fixed effect, we kept the later specification in all our regression models. 


\section{DISCUSSION AND CONCLUSION}

\section{Implications for Literature}

Our before/after analysis of the articles of attendees and matched non-attendees at Gordon Research Conferences shows that temporary colocation at a conference produces new collaborations and citations among scientists who had not previously worked with or cited others at the conference, and leads scientists who had worked with others to extend their collaborations. This work contributes to the literature by highlighting the dimension of time to proximity, which acts as a catalyst that facilitates matching of potential collaborators for long-term collaborative outputs. As compared to existing studies, in which individuals all come from the same institution and are located within a small physical radius (Biancani et al., 2014; Boudreau et al., 2017; Ingram et al., 2007), our study uses an empirical context with a cleaner temporary colocation setting and assesses its effects beyond the boundaries of an organization. By measuring real outcomes of temporary colocation through publication records, our findings suggest that spillover and collaborative ties can form even for short-term interactions outside the boundaries of organizations.

Moreover, temporary colocation across organizations impacts participants’ co-creation of knowledge differently depending on their research characteristics. We find that participants with established prior ties to the conference draw more collaborative benefits than do others. Junior researchers also benefit more collaboratively, although they are less likely to attend the conference. We also find that those located closer to the conference are not only more likely to attend, but also reap more collaborative benefits. The documented selectivity indicates that part of the observed pattern reflects the role of the conference as a pathway toward collaboration and 
knowledge exchange (presumably at lower cost than alternatives) rather than a purely causal impact.

Taken together, our results suggest that although individuals have agency when deciding whether to attend, conferences (and, by extension, related forms of temporary colocation across organizations) have the potential to yield collaborative and spillover benefits qualitatively similar to those generated by permanent colocation. Thus, this work introduces the dimension of time to the literature on agglomeration (Alcacer et al., 2007; Jaffe et al., 1993; Thompson et al., 2005) on top of the dimension of boundaries to the literature on proximity (Allen, 1977; Catalini, 2017; Fayard et al., 2007). Our findings suggest that firms can acquire external knowledge and capabilities (Cohen et al., 1990) not only through permanent colocation with other firms (Alcacer et al., 2007) but also by colocating their employees temporarily through external links (Cockburn et al., 1998).

Not surprisingly, we find that the ties formed at conferences tend to be distant (Sorenson et al., 2008) rather than local ties, as many participants travel long distances to attend (Figure 1D). Distant ties tend to be structurally less cohesive and more diverse than local ties. With short colocation timeframes, the number of collaborative trials decreases, and potential collaborators are forced to concentrate more on their work. Moreover, bringing distant researchers together expose attendees to a more diverse set of ideas, as distance limits the homogenization of ideas.

\section{Implications for Practice}

In the United States alone, approximately 25,000 professional research conferences are held each year, with yearly attendance increasing 54\% from 2002 to 2008 (SAB, 2013). Despite

these trends, the debate regarding the impact of such meetings has remained active. Scientists are advised to attend conferences to further their academic careers, but at the cost of diverted 
funding and potential productivity loss while away from their desks or benches. Despite such critiques, we find conferences to be worthwhile in terms of enabling scientists to find suitable collaborators and disseminate their work.

Our analysis also has implications for the evaluation of conferences and meetings. Many conferences assess their successes and failures with short surveys of attendees but do not collect follow-up information on attendees' post-conference work behavior. Our analysis shows that by combining lists of attendees with bibliometric data on publications, conference organizers can develop objective indicators of the impact of their conference to assess whether it is meeting their goals.

Moreover, our results suggest that policymakers in scientific funding agencies should consider supporting and fostering temporary colocation events beyond organizational boundaries as an effective form of proximity beyond researchers' usual sphere of interactions. Similarly, managers of science and technology-intensive firms should pledge substantial funds for employees to participate in professional or academic conferences, as these events impact the subsequent direction of R\&D activities. Thus, this work adds an inter-organizational channel that managers can use to enhance awareness, collaborations, and knowledge transfer outside of the firm's boundaries. This is important, given research showing that diverse views and breadth of knowledge lead to more impactful and creative innovations (Simonton, 1999). Our findings also speak to the internal work structure within firms with regard to temporary projects and "teaming" (Edmondson, 2012), such as rotational programs or skunkworks projects, by showing that the channels of ties formed can persist well beyond temporary interactions. 


\section{Limitations, Boundary Conditions and Future Research}

One limitation of our work is that it may not have fully eliminated issues surrounding the strategic choice of attending the conference. We believe that including and embracing this selection effect in our analysis is important, especially as it is a more accurate depiction of reality. Still, limitations are present, although we addressed endogeneity to the best of our ability through participant matching and DiD modeling, by isolating collaborations between attendees who have not published together or cited each other before, and by instrumenting attendance. For instance, with regard to the instrumental variable of distance we used, there might be other channels through which the sharing of ideas and collaborating are related to geography, and the fact that the choice of conference location is not random and tends to be located in New England or California. However, as discussed in the robustness test, regressions using the Plymouth indicator yielded similar results as using conference fixed effects.

Comparing the effect sizes between the instrumented and un-instrumented results, we find that the instruments attenuate the effects by several orders of magnitude, which can be taken as a sign that the variables used to predict attendance can account for some of the endogeneity issues we have discussed throughout. Knowing which invitees did not come and which scientists sought to come but were turned away could lead us beyond our analysis of the determinants of attendee choice and selectivity.

Our findings may also be limited to smaller events with a specialized theme, as the shared interest and language between attendees are more likely to heighten knowledge flow. Hence, given the wide range of structural variation at conferences in number of participants (small to moderately sized events such as the GRCs to annual meetings of 10,000 or more attendees), length (from one day to a week), topic concentration (single versus multi-topic), location (urban 
versus rural), and structure (parallel versus sequential sessions; number of plenary sessions), further work comparing and experimenting with the attributes of existing setups could improve their efficacy.

Our findings can be further extended and generalized to other temporary colocation events beyond organizational boundaries, such as industrial meetings, trade shows, alumni meetings, and professional mixers, both in terms of the strategic choice of temporarily colocating and its subsequent effects. Of course, the exchange of information is likely to be more constrained in industry than in academic interactions due to heightened concerns about intellectual property protection to sustain competitive advantage. Moreover, the locus of decision making for establishing formal collaborations between organizations may rest at a higher level.

Finally, the widespread penetration of the Internet raises another dimension of proximity, namely virtual proximity. Virtual conferences increasingly are being organized as a cheaper alternative to physical ones. Such examinations would help event organizers design setups that would be most effective for their goals. We hope this study motivates others to further understand how different forms of proximity affect knowledge diffusion and co-creation. 


\section{REFERENCES}

Agrawal A, Cockburn I, Rosell C. 2010. Not invented here? Innovation in company towns. Journal of Urban Economics 67(1): 78-89.

Agrawal A, Goldfarb A. 2008. Restructuring Research: Communication Costs and the Democratization of University Innovation. American Economic Review 98(4): 1578-1590.

Alcacer J, Chung W. 2007. Location strategies and knowledge spillovers. Management Science 53(5): 760-776.

Allen TJ. 1977. Managing the flow of technology : technology transfer and the dissemination of technological information within the R\&D organization. MIT Press: Cambridge, Mass.

Almeida P, Kogut B. 1999. Localization of Knowledge and the Mobility of Engineers in Regional Networks. Management Science 45(7): 905-917.

Anselin L, Varga A, Acs Z. 1997. Local geographic spillovers between university research and high technology innovations. Journal of Urban Economics 42(3): 422-448.

Audretsch DB, Feldman MP. 2004. Knowledge Spillovers and the Geography of Innovation. In Handbook of Urban and Regional Economics. Henderson JV, Thisse JF (eds.): North-Holland,

Amsterdam.

Basalla G. 1988. The evolution of technology. Cambridge University Press.

Becker F, Sims W, Schoss JH. 2003. Interaction, identity and collocation: What value is a corporate campus? Journal of Corporate Real Estate 5(4): 344-365.

Biancani S, McFarland DA, Dahlander L. 2014. The semiformal organization. Organization Science 25(5): 1306-1324.

Boudreau K, Ganguli I, Gaule P, Guinan E, Lakhani K. 2017. A Field Experiment on Search Costs and the Formation of Scientific Collaborations. Review of Economics \& Statistics.

Breschi S, Malerba F. 2001. The Geography of Innovation and Economic Clustering: Some Introductory

Notes. Industrial \& Corporate Change 10(4): 817-833.

Catalini C. 2017. Microgeography and the Direction of Innovative Activity. Management Science

forthcoming.

Chown JD, Liu CC. 2015. Geography and power in an organizational forum: Evidence from the U.S.

Senate Chamber. Strategic Management Journal 36(2): 177-196.

Chung W, Alcacer J. 2002. Knowledge seeking and location choice of foreign direct investment in the

United States. Management Science 48(12): 1534-1554.

Cockburn IM, Henderson RM. 1998. Absorptive Capacity, Coauthoring Behavior, and the Organization

of Research in Drug Discovery. The Journal of Industrial Economics 46(2): 157-182.

Cohen WM, Levinthal DA. 1990. Absorptive Capacity: A New Perspective on Learning and Innovation.

Administrative Science Quarterly 35(1): 128-152.

Coleman JS. 1988. Social Capital in the Creation of Human Capital. The American Journal of Sociology

94: S95-S120.

Edmondson AC. 2012. Teaming: How organizations learn, innovate, and compete in the knowledge economy. John Wiley \& Sons.

Fafchamps M, van der Leij MJ, Goyal S. 2010. Matching and Network Effects. Journal of the European Economic Association 8(1): 203-231.

Fayard A-L, Weeks J. 2007. Photocopiers and Water-coolers: The Affordances of Informal Interaction. Organization Studies 28(5): 605-634.

Feld SL. 1981. The focused organization of social ties. American journal of sociology 86(5): 1015-1035.

Feldman MP, Kogler DF. 2010. Chapter 8 - Stylized Facts in the Geography of Innovation. In

Handbook of the Economics of Innovation. Bronwyn HH, Nathan R (eds.), North-Holland.

Festinger L, Back KW, Schachter S. 1950. Social pressures in informal groups: A study of human factors in housing. Stanford University Press.

Fleming L. 2001. Recombinant Uncertainty in Technological Search. Management Science 47(1): 117132. 
Fleming L, Waguespack DM. 2007. Brokerage, boundary spanning, and leadership in open innovation communities. Organization science 18(2): 165-180.

Freeman RB, Huang W. 2015. Collaborating with people like me: Ethnic coauthorship within the United

States. Journal of Labor Economics 33(S1): S289-S318.

Ghemawat P. 1991. Commitment. Simon and Schuster.

Grandori A. 2009. Poliarchic governance and the growth of knowledge. Knowledge governance:

Process and perspectives: 81-107.

Gulati R. 1998. Alliances and networks. Strategic management journal 19(4): 293-317.

Hargadon A, Sutton RI. 1997. Technology Brokering and Innovation in a Product Development Firm.

Administrative Science Quarterly 42(4): 716-749.

Hinds PJ, Cramton CD. 2013. Situated coworker familiarity: How site visits transform relationships

among distributed workers. Organization Science 25(3): 794-814.

Ingram P, Morris MW. 2007. Do people mix at mixers? Structure, homophily, and the "life of the party”. Administrative Science Quarterly 52(4): 558-585.

Jaffe AB. 1989. Real Effects of Academic Research. The American Economic Review 79(5): 957-970.

Jaffe AB, Trajtenberg M, Henderson R. 1993. Geographic Localization of Knowledge Spillovers as

Evidenced by Patent Citations. The Quarterly Journal of Economics 108(3): 577-598.

Jones BF. 2009. The Burden of Knowledge and the "Death of the Renaissance Man": Is Innovation

Getting Harder? Review of Economic Studies 76(1): 283-317.

Katz J. 1994. Geographical proximity and scientific collaboration. Scientometrics 31(1): 31-43.

Kleinbaum AM, Stuart TE. 2014. Inside the black box of the corporate staff: Social networks and the implementation of corporate strategy. Strategic Management Journal 35(1): 24-47.

Kleinbaum AM, Stuart TE, Tushman ML. 2013. Discretion within constraint: Homophily and structure in a formal organization. Organization Science 24(5): 1316-1336.

Kogut B, Zander U. 1992. Knowledge of the Firm, Combinative Capabilities, and the Replication of

Technology. Organization Science 3(3): 383-397.

Liu CC, Srivastava SB, Stuart TE. 2015. An intraorganizational ecology of individual attainment.

Organization Science 27(1): 90-105.

Mansfield E. 1972. Contribution of R\&D to Economic Growth in the United States. Science 175(4021): 477-486.

McFadyen MA, Cannella AAJ. 2004. Social Capital and Knowledge Creation: Diminishing Returns of the Number and Strength of Exchange Relationships Academy of Management Journal 47(5): 735-746.

McPherson M, Smith-Lovin L, Cook JM. 2001. Birds of a feather: Homophily in social networks.

Annual review of sociology 27(1): 415-444.

Obstfeld D. 2005. Social Networks, the Tertius Iungens Orientation, and Involvement in Innovation.

Administrative Science Quarterly 50(1): 100-130.

Oldham GR, Brass DJ. 1979. Employee reactions to an open-plan office: A naturally occurring quasi-

experiment. Administrative Science Quarterly: 267-284.

Rosenberg N. 1974. Science, Invention and Economic Growth. The Economic Journal 84(333): 90-108.

Rosenkopf L, Metiu A, George VP. 2001. From the Bottom Up? Technical Committee Activity and

Alliance Formation. Administrative Science Quarterly 46(4): 748-772.

Ruef M, Aldrich HE, Carter NM. 2003. The structure of founding teams: Homophily, strong ties, and isolation among US entrepreneurs. American sociological review: 195-222.

SAB. 2013. Trends in Scientific Conferences, Science Advisory Board:

http://www.scienceboard.net/studies/studies.asp?studyId=142.

Saxenian A. 1994. Regional advantage: Culture and competition in Silicon Valley and Route 128.

Harvard University, Cambridge, MA.

Shaver JM, Flyer F. 2000. Agglomeration economies, firm heterogeneity, and foreign direct investment in the United States. Strategic Management Journal 21(12): 1175-1194.

Simonton DK. 1999. Origins of genius: Darwinian perspectives on creativity. Oxford University Press: Oxford. 
Singh J, Fleming L. 2010. Lone Inventors as Sources of Breakthroughs: Myth or Reality? Management Science 56(1): 41-56.

Sohn E. 2017. Reverse Knowledge Spillovers from Industry to Academia: Evidence from the Agricultural Biotechnology Revolution. Working paper.

Sommer R. 1959. Studies in personal space. Sociometry 22(3): 247-260.

Sorenson O, Stuart TE. 2008. Bringing the context back in: Settings and the search for syndicate partners in venture capital investment networks. Administrative Science Quarterly 53(2): 266-294.

Stuart TE, Podolny JM. 1996. Local Search and the Evolution of Technological Capabilities. Strategic Management Journal 17: 21-38.

Tham WY. 2018. The Effect of Temporary Colocation on Knowledge Flows. Working paper.

Thompson P, Fox-Kean M. 2005. Patent Citations and the Geography of Knowledge Spillovers: A

Reassessment: Reply. The American Economic Review 95(1): 465-466.

Torvik VI, Smalheiser NR. 2009. Author Name Disambiguation in MEDLINE. ACM transactions on knowledge discovery from data 3(3): 1-29.

Uzzi B. 1997. Social Structure and Competition in Interfirm Networks: The Paradox of Embeddedness. Administrative Science Quarterly 42(1): 35-67.

Wuchty S, Jones BF, Uzzi B. 2007. The Increasing Dominance of Teams in Production of Knowledge. Science 316(5827): 1036-1039.

Zipf GK. 1949. Human behavior and the principle of least effort: an introduction to human ecology. Addison-Wesley Press. 

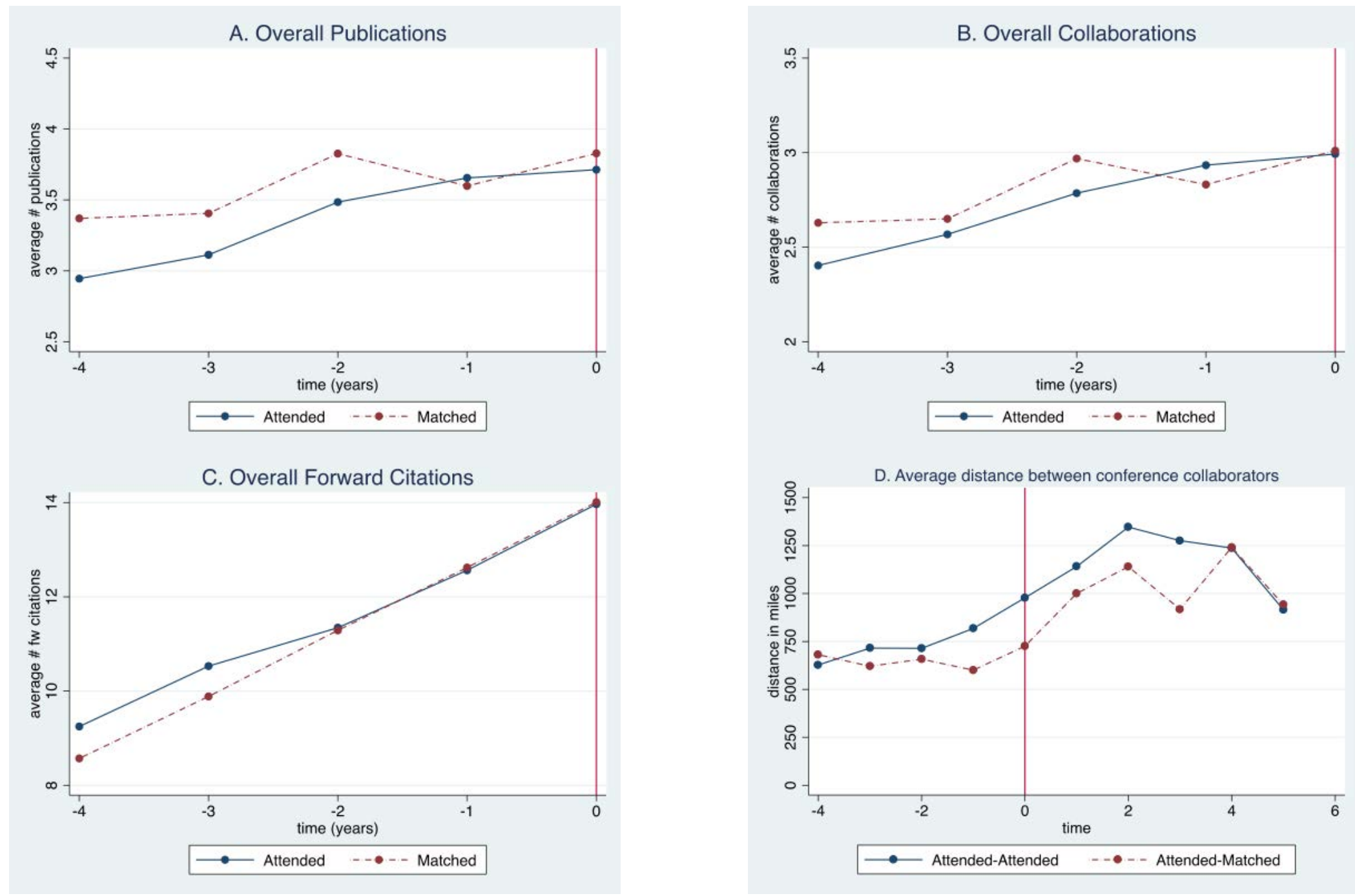

Figure 1. Yearly average trends before the conference, including overall publications, collaborations, and forward citations for attendees and nonattendees for the full sample, as well as yearly trends before and after the conference of the average collaborative distance for publications between attendees and non-attendees. 


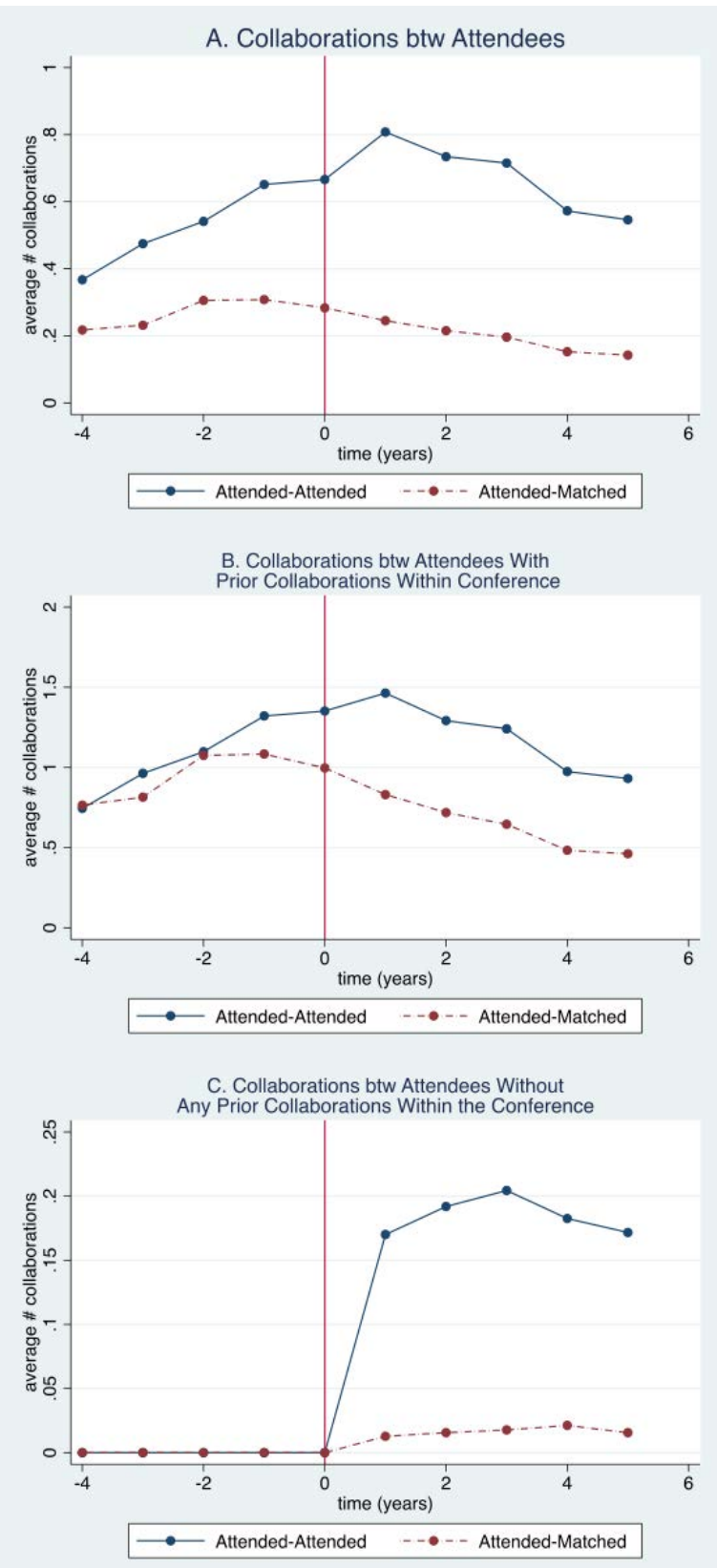

Figure 2. Raw yearly average trends before and after the conference of collaborations among attendees and non-attendees for the full sample. 
Table 1. The 15 GRCs in our sample.

\begin{tabular}{rlrl}
\hline \# & \multicolumn{1}{c}{ Conference Topic } & Year & \multicolumn{1}{c}{ Location } \\
\hline 1 & Meiosis & 1992 & Plymouth State College, Plymouth, NH \\
2 & Mitochondria \& Chloroplasts & 1992 & Plymouth State College, Plymouth, NH \\
3 & Molecular Cytogenetics & 1992 & Ventura Beach Marriott, Ventura CA \\
4 & NeuroEndocroImmunology & 1992 & Casa Sirena Hotel, Oxnard, CA \\
5 & Calcium Signalling & 1993 & New England College, Henniker, NH \\
6 & Matrix Metalloproteinases & 1993 & Plymouth State College, Plymouth, NH \\
7 & Neurotrophins & 1993 & Plymouth State College, Plymouth, NH \\
8 & Wound Repair & 1993 & Colby-Sawyer College, New London, NH \\
9 & Hormomal and Neural Peptide & 1994 & Plymouth State College, Plymouth, NH \\
10 & Oxygen Binding Proteins & 1994 & Plymouth State College, Plymouth, NH \\
11 & Salinity Tolerance in Plants & 1994 & Tilton School, Tilton, NH \\
12 & Angiogenesis \& Microcirculation & 1995 & Salve Regina University, Newport, RI \\
13 & Human Molecular Genetics & 1995 & Salve Regina University, Newport, RI \\
14 & Cell Death & 1995 & Colby-Sawyer College, New London, NH \\
15 & Epigenetics & 1995 & Holderness School, Holderness, NH \\
\hline
\end{tabular}

Table 2. A comparison of attended and matched researcher observables based on five-year average measures prior to conference.

\begin{tabular}{l|rrr}
\hline \multicolumn{1}{c|}{ Characteristic } & Attended & \multicolumn{1}{c}{ Matched } & $\begin{array}{c}\text { Two tailed } \\
\text { t-test }\end{array}$ \\
\hline experience & 13.2 & 12.57 & 0.09 \\
publications & 3.38 & 3.61 & 0.3 \\
collaborations & 2.74 & 2.82 & 0.59 \\
citations & 11.53 & 11.28 & 0.78 \\
\hline $\mathrm{n}$ & 1265 & 2016 & \\
\hline
\end{tabular}


Table 3. Summary statistics for variables used in the main analysis, and the variation in effect conditional on attendance.

\begin{tabular}{|c|c|c|c|c|c|c|}
\hline Variable & Description & \# Obs & Mean & Std. Dev. & Min & Max \\
\hline $\begin{array}{l}\text { Full sample } \\
\text { publications }\end{array}$ & peer-reviewed publications produced & 32,380 & 3.63181 & 6.417172 & 0 & 131 \\
\hline collaborations & publications written with one or multiple co-authors & 32,380 & 2.888789 & 4.710739 & 0 & 130 \\
\hline $\begin{array}{l}\text { collaborations between } \\
\text { attendees }\end{array}$ & $\begin{array}{l}\text { collaborations btw attendees for attendee group or btw } \\
\text { attendee \& matched for counterfactual group }\end{array}$ & 32,380 & 0.3772082 & 1.124933 & 0 & 21 \\
\hline post & indicator=1 after the conference & 32,380 & 0.5 & 0.5000077 & 0 & 1 \\
\hline attended & indicator=1 for attendees & 32,380 & 0.3903644 & 0.4878395 & 0 & 1 \\
\hline post*attended & interaction effect of post and attended indicators & 32,380 & 0.1951822 & 0.396347 & 0 & 1 \\
\hline multiple attendance & indicator=1 if attended more than one conference in sample & 32,380 & 0.0077208 & 0.0875297 & 0 & 1 \\
\hline experience & years from first publication to conference year & 32,380 & 12.9824 & 9.945433 & 0 & 51 \\
\hline similar dimensions & \# similar dimensions with conference attendee average & 32,380 & 3.876776 & 1.849175 & 0 & 6 \\
\hline distance & miles from primary affiliation to conference & 29,790 & 2385.923 & 2084.637 & 25.5032 & 11530.45 \\
\hline average collaborative distance & average distance btw all collaborators on same pub & 5,420 & 1030.07 & 1669.23 & 0 & 11862.38 \\
\hline citations & forward citations pubs garnered in 5 years after pub & 32,380 & 2.888789 & 4.710739 & 0 & 130 \\
\hline citations between attendees & $\begin{array}{l}\text { forward citations btw attendees for attendee group or btw } \\
\text { attendee \& matched for counterfactual group }\end{array}$ & 32,380 & 0.3772082 & 1.124933 & 0 & 21 \\
\hline $\begin{array}{l}\text { Conditional on attendance sam } \\
\text { collaborations between } \\
\text { attendees }\end{array}$ & collaborations btw attendees & 6,320 & 0.6751582 & 1.467164 & 0 & 18 \\
\hline common $\mathrm{MeSH}$ & \# MeSH in common with conference & 6,320 & 15.06756 & 15.94559 & 0 & 101 \\
\hline prior collaborations & collaborations btw attendees before conference & 6,320 & 2.700158 & 5.573841 & 0 & 59 \\
\hline prior citations & citations btw attendees before conference & 6,320 & 10.24209 & 32.92565 & 0 & 607 \\
\hline Junior & indicator $=1$ if experience $<=10$ & 6,320 & 0.4509494 & 0.4976276 & 0 & 1 \\
\hline similar dimensions & \# similar dimensions with conference attendee average & 6,320 & 3.829905 & 1.854501 & 0 & 6 \\
\hline distance & miles from primary affiliation to conference & 5,520 & 1957.542 & 1860.209 & 30.22946 & 10730.08 \\
\hline
\end{tabular}


Table 4. Main effect of temporary colocation on collaboration. 2SLS instrumental variable (IV) OLS model for the full sample with coefficients and standard errors in parentheses. Models 1 to 3 use post*instruments as instruments for post*attended due to its differences-in-difference setup, whereas Model 4 uses the actual instruments for attended. The dependent variables for the second stage are respectively the natural logarithm of 1+ the (a) overall collaborations in Model 1, (b) collaborations between attendees in Model 2, (c) collaborations between attendees with prior collaborative links within the conference in Model 3, and (d) collaborations between attendees with no prior collaborative links within the conference in Model 4. Robust standard errors are in parentheses with clustering on the individual. Individual fixed effects are included for Models 1 to 3, and conference fixed effects are also included for all models.

\begin{tabular}{|c|c|c|c|c|c|c|c|c|}
\hline & \multicolumn{2}{|c|}{ Model 1} & \multicolumn{2}{|c|}{ Model 2} & \multicolumn{2}{|c|}{ Model 3} & \multicolumn{2}{|c|}{ Model 4} \\
\hline & $1^{\text {st }} \mathrm{S}$ & 2SLS & $1^{\text {st }} \mathrm{S}$ & 2SLS & $1^{\text {st }} \mathrm{S}$ & 2SLS & $1^{\text {st }} \mathrm{S}$ & 2SLS \\
\hline post & 0.6026 & -0.0120 & 0.6026 & 0.0008 & 0.4456 & -0.1855 & & \\
\hline & $(0.0201)$ & $(0.0063)$ & $(0.0201)$ & $(0.0140)$ & $(0.0325)$ & $(0.0465)$ & & \\
\hline attended & & & & & & & & $\begin{array}{r}0.0896 \\
(0.0227)\end{array}$ \\
\hline post*attended & & $\begin{array}{r}0.0204 \\
(0.0177)\end{array}$ & & $\begin{array}{r}-0.0185 \\
(0.0388)\end{array}$ & & $\begin{array}{r}0.1784 \\
(0.0901)\end{array}$ & & \\
\hline post*ln(distance) & $\begin{array}{r}-0.0543 \\
(0.0022)\end{array}$ & & $\begin{array}{r}-0.0543 \\
(0.0022)\end{array}$ & & $\begin{array}{r}-0.0131 \\
(0.0037)\end{array}$ & & & \\
\hline post*ln(experience) & $\begin{array}{r}0.0547 \\
(0.0034)\end{array}$ & & $\begin{array}{r}0.0547 \\
(0.0034)\end{array}$ & & $\begin{array}{r}0.0801 \\
(0.0058)\end{array}$ & & & \\
\hline $\begin{array}{l}\text { post*similar } \\
\text { dimensions }\end{array}$ & $\begin{array}{r}0.0049 \\
(0.0016)\end{array}$ & & $\begin{array}{r}0.0049 \\
(0.0016)\end{array}$ & & $\begin{array}{r}-0.0067 \\
(0.0027)\end{array}$ & & & \\
\hline $\ln$ (distance) & & & & & & & $\begin{array}{r}-0.0658 \\
(0.0038)\end{array}$ & \\
\hline $\ln$ (experience) & & & & & & & $\begin{array}{r}0.0199 \\
(0.0060)\end{array}$ & \\
\hline similar dimensions & & & & & & & $\begin{array}{r}0.0047 \\
(0.0027)\end{array}$ & \\
\hline multiple attendance & & & & & & & $\begin{array}{r}0.0071 \\
(0.0519)\end{array}$ & $\begin{array}{r}-0.0179 \\
(0.0174)\end{array}$ \\
\hline $\ln$ (publications) & $\begin{array}{r}0.0393 \\
(0.0029)\end{array}$ & $\begin{array}{r}0.9127 \\
(0.0027)\end{array}$ & $\begin{array}{r}0.0393 \\
(0.0029)\end{array}$ & $\begin{array}{r}0.2300 \\
(0.0045)\end{array}$ & $\begin{array}{r}0.0366 \\
(0.0046)\end{array}$ & $\begin{array}{r}0.4850 \\
(0.0084)\end{array}$ & $\begin{array}{r}0.0430 \\
(0.0061)\end{array}$ & $\begin{array}{r}0.0340 \\
(0.0031)\end{array}$ \\
\hline $\ln$ (citations) & $\begin{array}{r}0.0200 \\
(0.0027)\end{array}$ & $\begin{array}{r}0.0106 \\
(0.0024)\end{array}$ & $\begin{array}{r}0.0200 \\
(0.0027)\end{array}$ & $\begin{array}{r}0.0017 \\
(0.0033)\end{array}$ & $\begin{array}{r}0.0220 \\
(0.0046)\end{array}$ & $\begin{array}{r}0.0148 \\
(0.0071)\end{array}$ & $\begin{array}{r}-0.0147 \\
(0.0041)\end{array}$ & $\begin{array}{r}-0.0045 \\
(0.0016)\end{array}$ \\
\hline constant & & & & & & & $\begin{array}{r}0.6436 \\
(0.0414) \\
\end{array}$ & $\begin{array}{r}0.0089 \\
(0.0118) \\
\end{array}$ \\
\hline individual fe & $\mathrm{y}$ & $\mathrm{y}$ & $\mathrm{y}$ & $\mathrm{y}$ & $\mathrm{y}$ & $\mathrm{y}$ & & \\
\hline conference fe & $\mathrm{y}$ & $\mathrm{y}$ & $\mathrm{y}$ & $\mathrm{y}$ & $\mathrm{y}$ & $\mathrm{y}$ & $\mathrm{y}$ & $\mathrm{y}$ \\
\hline $\mathrm{N}$ & 29790 & 29790 & 29790 & 29790 & 11510 & 11510 & 9140 & 9140 \\
\hline $\mathrm{R} 2$ & & 0.9356 & & 0.1569 & & 0.3558 & & 0.1184 \\
\hline F-stat & 299.6 & & 299.6 & & 76.48 & & 107.3 & \\
\hline
\end{tabular}


Table 5. Variation in effect of temporary colocation depending on participant characteristics conditional on attendance. The table shows QML Poisson count regression models with panel random effects and robust standard errors in parentheses. The dependent variables are respectively: (a) collaborations between attendees in Model 1, and (b) number of common MeSH keywords with the conference in Model 2. Conference and time fixed effects are included for all models.

\begin{tabular}{|c|c|c|}
\hline & $\begin{array}{c}\text { Model } 1 \\
\text { collaborations } \\
\text { btw attendees }\end{array}$ & $\begin{array}{l}\text { Model } 2 \\
\text { common } \\
\text { MeSH }\end{array}$ \\
\hline $\ln$ (publications) & $\begin{array}{r}1.308 \\
(0.0594)\end{array}$ & $\begin{array}{r}1.084 \\
(0.0199)\end{array}$ \\
\hline $\ln$ (citations) & $\begin{array}{r}-0.162 \\
(0.0309)\end{array}$ & $\begin{array}{r}-0.0281 \\
(0.0149)\end{array}$ \\
\hline multiple attendance & $\begin{array}{r}-1.402 \\
(0.498)\end{array}$ & $\begin{array}{r}-0.236 \\
(0.164)\end{array}$ \\
\hline $\ln$ (prior collaborations) & $\begin{array}{r}0.833 \\
(0.0471)\end{array}$ & $\begin{array}{r}-0.0105 \\
(0.0194)\end{array}$ \\
\hline $\ln$ (prior citations) & $\begin{array}{r}-0.148 \\
(0.0383)\end{array}$ & $\begin{array}{r}0.0700 \\
(0.0159)\end{array}$ \\
\hline $\ln$ (similar dimensions) & $\begin{array}{r}0.254 \\
(0.0785)\end{array}$ & $\begin{array}{r}0.159 \\
(0.0316)\end{array}$ \\
\hline junior & $\begin{array}{r}0.497 \\
(0.0854)\end{array}$ & $\begin{array}{r}0.00305 \\
(0.0296)\end{array}$ \\
\hline $\ln$ (distance) & $\begin{array}{r}-0.0672 \\
(0.0286)\end{array}$ & $\begin{array}{r}-0.0188 \\
(0.0102)\end{array}$ \\
\hline constant & $\begin{array}{r}-3.639 \\
(0.349)\end{array}$ & $\begin{array}{r}0.991 \\
(0.127)\end{array}$ \\
\hline $\begin{array}{l}\text { Inalpha } \\
\text { constant }\end{array}$ & $\begin{array}{r}-0.289 \\
(0.446)\end{array}$ & $\begin{array}{l}-1.033 \\
(0.630)\end{array}$ \\
\hline conference fe & $\mathrm{y}$ & $\mathrm{y}$ \\
\hline $\mathrm{N}$ & 5520 & 5520 \\
\hline Log lik. & -4462.2 & -17537.9 \\
\hline
\end{tabular}

Standard errors in parentheses 


\section{APPENDIX}

Table A1. Correlation matrices for the full and conditional on attendance samples

\begin{tabular}{|c|c|c|c|c|c|c|c|c|c|c|c|}
\hline Full sample & publications & collaborations & $\begin{array}{c}\text { collaborations } \\
\text { between } \\
\text { attendees }\end{array}$ & post & attended & $\begin{array}{c}\text { post* } \\
\text { attended }\end{array}$ & $\begin{array}{c}\text { multiple } \\
\text { attendance }\end{array}$ & experience & $\begin{array}{c}\text { similar } \\
\text { dimensions }\end{array}$ & distance & $\begin{array}{c}\text { average } \\
\text { collaborative } \\
\text { distance }\end{array}$ \\
\hline publications & 1 & & & & & & & & & & \\
\hline collaborations & 0.8252 & 1 & & & & & & & & & \\
\hline $\begin{array}{l}\text { collaborations } \\
\text { between attendees }\end{array}$ & 0.3868 & 0.4423 & 1 & & & & & & & & \\
\hline post & 0.0809 & 0.1002 & 0.032 & 1 & & & & & & & \\
\hline attended & -0.0343 & 0.0781 & 0.0509 & 0.1336 & 1 & & & & & & \\
\hline post*attended & 0.0107 & 0.0897 & 0.0408 & 0.7181 & 0.5577 & 1 & & & & & \\
\hline multiple attendance & 0.0787 & 0.0569 & 0.0475 & -0.0076 & 0.0325 & 0.0111 & 1 & & & & \\
\hline experience & 0.2426 & 0.2429 & 0.1162 & -0.004 & 0.0353 & -0.0191 & 0.0039 & 1 & & & \\
\hline similar dimensions & -0.3657 & -0.4036 & -0.2263 & -0.0121 & -0.0673 & -0.0369 & -0.1106 & -0.2575 & 1 & & \\
\hline $\begin{array}{l}\text { distance } \\
\text { average } \\
\text { collaborative } \\
\text { distance }\end{array}$ & 0.0299 & 0.0463 & -0.0848 & 0.0179 & -0.0131 & -0.0013 & -0.0598 & -0.0164 & -0.0143 & 0.1898 & 1 \\
\hline
\end{tabular}

\begin{tabular}{|c|c|c|c|c|c|c|c|}
\hline $\begin{array}{l}\text { Conditional on attendance } \\
\text { sample }\end{array}$ & $\begin{array}{c}\text { collaborations } \\
\text { between attendees }\end{array}$ & $\begin{array}{c}\text { common } \\
\text { MeSH }\end{array}$ & $\begin{array}{c}\text { prior } \\
\text { collaborations } \\
\end{array}$ & prior citations & junior & $\begin{array}{c}\text { similar } \\
\text { dimensions }\end{array}$ & distance \\
\hline $\begin{array}{l}\text { collaborations between } \\
\text { attendees }\end{array}$ & 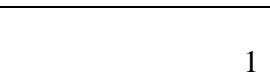 & & & & & & \\
\hline common MeSH & 0.419 & 1 & & & & & \\
\hline prior collaborations & 0.5277 & 0.2901 & 1 & & & & \\
\hline prior citations & 0.1729 & 0.2374 & 0.4272 & 1 & & & \\
\hline junior & -0.1068 & -0.2532 & -0.209 & -0.1738 & 1 & & \\
\hline similar dimensions & -0.1765 & -0.3721 & -0.3489 & -0.2591 & 0.1849 & 1 & \\
\hline distance & 0.0708 & 0.0166 & 0.007 & -0.031 & 0.0359 & 0.0147 & 1 \\
\hline
\end{tabular}


Table A2. Variation in effect of temporary colocation on collaboration depending on participant characteristics conditional on attendance. The table shows QML Poisson count regression models with panel random effects and robust standard errors in parentheses. The dependent variable is betweenattendee collaborations. Conference and time fixed effects are included for all models.

\begin{tabular}{|c|c|c|c|c|c|}
\hline $\begin{array}{l}\text { Collaborations btw } \\
\text { attendees }\end{array}$ & Model 1 & Model 2 & Model 3 & Model 4 & Model 5 \\
\hline \multirow[t]{2}{*}{$\ln$ (publications) } & 1.483 & 1.342 & 1.343 & 1.368 & 1.308 \\
\hline & $(0.0387)$ & $(0.0635)$ & $(0.0633)$ & $(0.0589)$ & $(0.0594)$ \\
\hline \multirow[t]{2}{*}{$\ln$ (citations) } & -0.167 & -0.205 & -0.206 & -0.183 & -0.162 \\
\hline & $(0.0258)$ & $(0.0305)$ & $(0.0305)$ & (0.0295) & (0.0309) \\
\hline \multirow[t]{2}{*}{ multiple attendance } & -0.562 & -1.632 & -1.625 & -1.396 & -1.402 \\
\hline & $(0.518)$ & $(0.509)$ & $(0.499)$ & $(0.532)$ & $(0.498)$ \\
\hline \multirow[t]{2}{*}{$\ln$ (prior collaborations) } & & 0.795 & 0.794 & 0.789 & 0.833 \\
\hline & & $(0.0487)$ & $(0.0483)$ & $(0.0468)$ & $(0.0471)$ \\
\hline \multirow[t]{2}{*}{ ln(prior citations) } & & -0.230 & -0.229 & -0.161 & -0.148 \\
\hline & & (0.0379) & $(0.0386)$ & $(0.0376)$ & $(0.0383)$ \\
\hline \multirow[t]{2}{*}{ ln(similar dimensions) } & & & 0.0619 & 0.106 & 0.254 \\
\hline & & & $(0.0828)$ & $(0.0748)$ & $(0.0785)$ \\
\hline \multirow[t]{2}{*}{ junior } & & & & 0.585 & 0.497 \\
\hline & & & & $(0.0810)$ & $(0.0854)$ \\
\hline \multirow[t]{2}{*}{$\ln$ (distance) } & & & & & -0.0672 \\
\hline & & & & & $(0.0286)$ \\
\hline \multirow[t]{2}{*}{ constant } & -3.248 & -3.372 & -3.437 & -3.848 & -3.639 \\
\hline & $(0.384)$ & $(0.270)$ & $(0.288)$ & $(0.299)$ & (0.349) \\
\hline \multicolumn{6}{|l|}{ lnalpha } \\
\hline \multirow[t]{2}{*}{ constant } & 0.308 & -0.154 & -0.158 & -0.220 & -0.289 \\
\hline & $(0.290)$ & $(0.404)$ & $(0.407)$ & $(0.408)$ & $(0.446)$ \\
\hline conference fe & $\mathrm{y}$ & $\mathrm{y}$ & $\mathrm{y}$ & $\mathrm{y}$ & $\mathrm{y}$ \\
\hline $\mathrm{N}$ & 6320 & 6320 & 6320 & 6320 & 5520 \\
\hline Log lik. & -5017.6 & -4885.0 & -4884.7 & -4857.6 & -4462.2 \\
\hline
\end{tabular}


Table A3. Variation in effect of temporary colocation on inventive direction depending on participant characteristics conditional on attendance. The table shows QML Poisson count regression models with panel random effects and robust standard errors in parentheses. The dependent variable is the number of common MeSH keywords. Conference and time fixed effects are included for all models.

\begin{tabular}{|c|c|c|c|c|c|}
\hline Common MeSH & Model 1 & Model 2 & Model 3 & Model 4 & Model 5 \\
\hline \multirow[t]{2}{*}{$\ln$ (publications) } & 1.143 & 1.139 & 1.139 & 1.139 & 1.084 \\
\hline & $(0.0202)$ & $(0.0205)$ & $(0.0205)$ & $(0.0205)$ & (0.0199) \\
\hline \multirow[t]{2}{*}{$\ln$ (citations) } & -0.0213 & -0.0295 & -0.0291 & -0.0291 & -0.0281 \\
\hline & $(0.0149)$ & $(0.0139)$ & $(0.0140)$ & $(0.0141)$ & $(0.0149)$ \\
\hline \multirow[t]{2}{*}{ multiple attendance } & -0.260 & -0.237 & -0.252 & -0.250 & -0.236 \\
\hline & $(0.168)$ & $(0.171)$ & $(0.168)$ & $(0.169)$ & $(0.164)$ \\
\hline \multicolumn{6}{|l|}{$\ln ($ prior } \\
\hline \multirow[t]{2}{*}{ collaborations) } & & -0.00794 & -0.0101 & -0.0103 & -0.0105 \\
\hline & & $(0.0197)$ & (0.0193) & $(0.0194)$ & $(0.0194)$ \\
\hline \multirow[t]{2}{*}{$\ln$ (prior citations) } & & 0.0578 & 0.0612 & 0.0618 & 0.0700 \\
\hline & & $(0.0159)$ & $(0.0160)$ & $(0.0158)$ & $(0.0159)$ \\
\hline \multirow[t]{2}{*}{$\ln$ (similar dimensions) } & & & 0.166 & 0.166 & 0.159 \\
\hline & & & $(0.0291)$ & $(0.0290)$ & $(0.0316)$ \\
\hline \multirow[t]{2}{*}{ junior } & & & & 0.00505 & 0.00305 \\
\hline & & & & $(0.0292)$ & $(0.0296)$ \\
\hline \multirow[t]{2}{*}{$\ln$ (distance) } & & & & & -0.0188 \\
\hline & & & & & $(0.0102)$ \\
\hline \multirow[t]{2}{*}{ constant } & 1.030 & 0.952 & 0.781 & 0.779 & 0.991 \\
\hline & $(0.0953)$ & $(0.0936)$ & $(0.111)$ & $(0.112)$ & $(0.127)$ \\
\hline \multicolumn{6}{|l|}{ lnalpha } \\
\hline \multirow[t]{2}{*}{ constant } & -0.953 & -0.960 & -0.979 & -0.979 & -1.033 \\
\hline & $(0.554)$ & $(0.550)$ & $(0.557)$ & $(0.557)$ & $(0.630)$ \\
\hline conference fe & $\mathrm{y}$ & $\mathrm{y}$ & $\mathrm{y}$ & $\mathrm{y}$ & $\mathrm{y}$ \\
\hline $\mathrm{N}$ & 6320 & 6320 & 6320 & 6320 & 5520 \\
\hline Log lik. & -19555.1 & -19547.8 & -19538.8 & -19538.8 & -17537.9 \\
\hline
\end{tabular}

Standard errors in parentheses 
Table A4. Main effect of temporary colocation on citations. 2SLS instrumental variable (IV) OLS model for the full sample with coefficients and standard errors in parentheses. Models 1 and 2 use post*instruments as instruments for post*attended due to its differences-in-difference setup, whereas Model 3 uses the actual instruments for attended. The dependent variables for the second stage are respectively the natural logarithm of $1+$ the (a) citations between attendees in Model 1, (b) citations between attendees with prior citation links within the conference in Model 2, and (c) citations between attendees with no prior citation links within the conference in Model 3. Robust standard errors are in parentheses with clustering on the individual. Individual fixed effects are included for Models 1 and 2, and conference fixed effects are also included for all models.

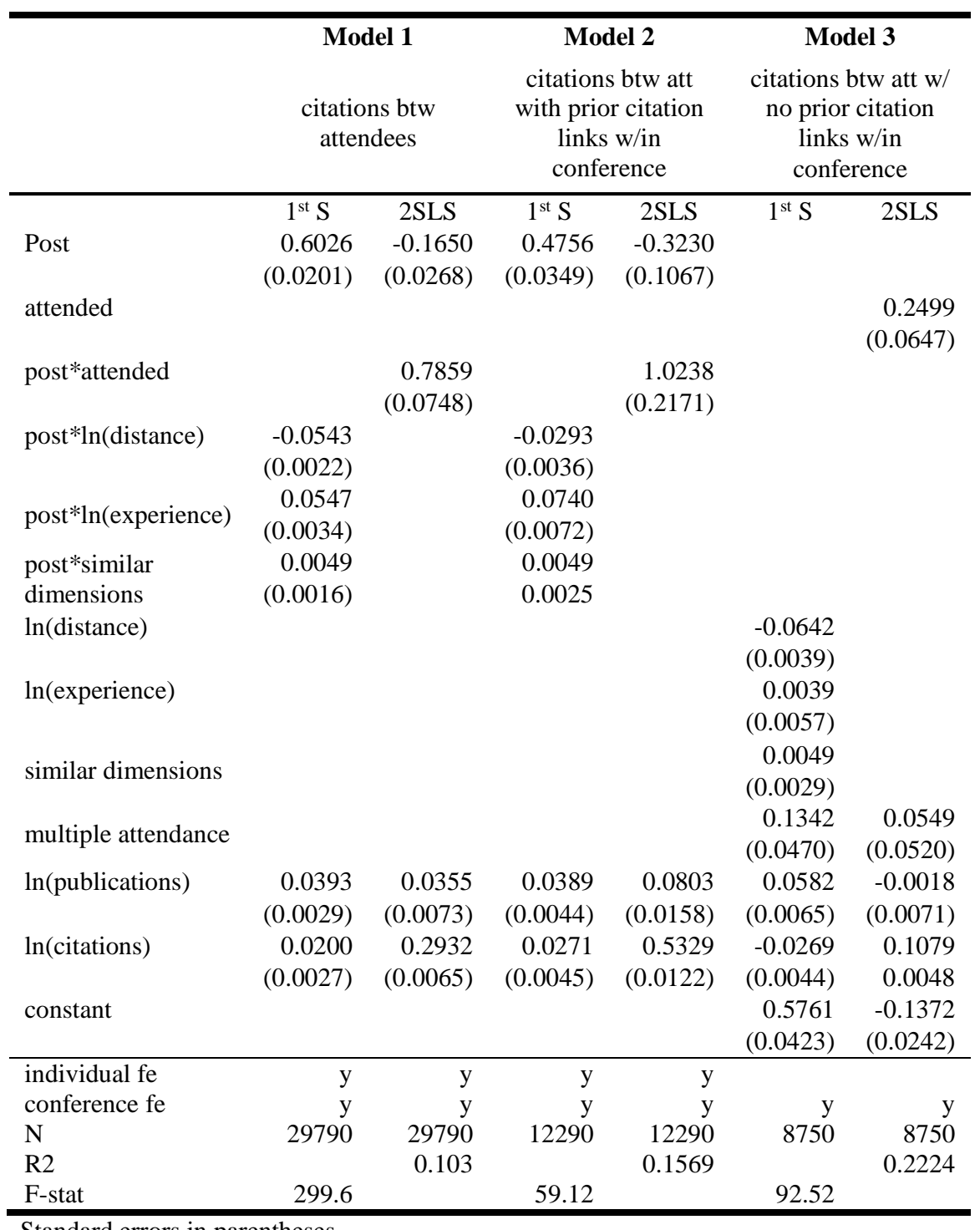

Standard errors in parentheses 
Table A5. Main effect of temporary colocation on collaboration. Difference-in-differences and simplified QML Poisson count regression models with panel random effects. The dependent variables are, respectively: (a) overall collaborations in Model 1, (b) between-attendee collaborations in Model 2, (c) collaborations from attendees with prior collaboration links within the conference in Model 3, (d) and collaborations from attendees with no prior collaboration links within the conference in Model 4. Robust standard errors are in parentheses with clustering on the individual. Conference fixed effects are also included.

\begin{tabular}{|c|c|c|c|c|}
\hline & Model 1 & $\begin{array}{c}\text { Model } 2 \\
\text { collaborations } \\
\text { btw att }\end{array}$ & $\begin{array}{c}\text { Model } 3 \\
\text { collaborations } \\
\text { btw att with } \\
\text { prior } \\
\text { collaboration } \\
\text { links w/in } \\
\text { conference }\end{array}$ & $\begin{array}{c}\text { Model } 4 \\
\text { collaborations } \\
\text { btw att w/ no } \\
\text { prior } \\
\text { collaboration } \\
\text { links w/in } \\
\text { conference }\end{array}$ \\
\hline post & $\begin{array}{r}-0.0230 \\
(0.0062)\end{array}$ & $\begin{array}{r}-0.334 \\
(0.0432)\end{array}$ & $\begin{array}{r}-0.373 \\
(0.0447)\end{array}$ & \\
\hline attended & $\begin{array}{r}0.0548 \\
(0.0138)\end{array}$ & $\begin{array}{r}0.757 \\
(0.0703)\end{array}$ & $\begin{array}{r}0.0649 \\
(0.0548)\end{array}$ & $\begin{array}{r}2.442 \\
(0.1770)\end{array}$ \\
\hline post*attended & $\begin{array}{r}0.0127 \\
(0.0086)\end{array}$ & $\begin{array}{r}0.342 \\
(0.0532)\end{array}$ & $\begin{array}{r}0.321 \\
(0.0550)\end{array}$ & \\
\hline $\ln$ (experience) & $\begin{array}{r}0.0426 \\
(0.0085)\end{array}$ & $\begin{array}{r}-0.337 \\
(0.0448)\end{array}$ & $\begin{array}{r}-0.254 \\
(0.0384)\end{array}$ & $\begin{array}{r}-0.460 \\
(0.0948)\end{array}$ \\
\hline $\ln$ (publications) & $\begin{array}{r}1.368 \\
(0.0387)\end{array}$ & $\begin{array}{r}1.524 \\
(0.0267)\end{array}$ & $\begin{array}{r}1.379 \\
(0.0486)\end{array}$ & $\begin{array}{r}1.531 \\
(0.1310)\end{array}$ \\
\hline $\ln$ (citations) & $\begin{array}{l}0.00214 \\
(0.0062)\end{array}$ & $\begin{array}{r}-0.0184 \\
(0.0244)\end{array}$ & $\begin{array}{r}-0.0668 \\
(0.0285)\end{array}$ & $\begin{array}{r}-0.0945 \\
(0.0641)\end{array}$ \\
\hline $\ln ($ distance) & $\begin{array}{l}0.00553 \\
(0.0052)\end{array}$ & $\begin{array}{r}-0.113 \\
(0.0289)\end{array}$ & $\begin{array}{c}-0.0187 \\
(0.0226)\end{array}$ & $\begin{array}{r}-0.125 \\
(0.0718)\end{array}$ \\
\hline constant & $\begin{array}{r}-1.308 \\
(0.0893)\end{array}$ & $\begin{array}{r}-2.000 \\
(0.3300)\end{array}$ & $\begin{array}{r}-1.553 \\
(0.2510)\end{array}$ & $\begin{array}{r}-4.764 \\
(0.6790)\end{array}$ \\
\hline $\begin{array}{l}\text { lnalpha } \\
\text { constant }\end{array}$ & $\begin{array}{r}-2.281 \\
(0.6950) \\
\end{array}$ & $\begin{array}{r}1.108 \\
(0.3990) \\
\end{array}$ & $\begin{array}{r}-0.549 \\
(0.4830) \\
\end{array}$ & $\begin{array}{r}1.001 \\
(0.7550) \\
\end{array}$ \\
\hline $\begin{array}{l}\text { conference fe } \\
\mathrm{N}\end{array}$ & $\begin{array}{r}\mathrm{y} \\
29790\end{array}$ & $\begin{array}{r}\mathrm{y} \\
29790\end{array}$ & $\begin{array}{r}\mathrm{y} \\
11510\end{array}$ & $\begin{array}{r}\mathrm{y} \\
9140\end{array}$ \\
\hline Log lik. & -37992.5 & -14993.9 & -11895.1 & -1405.7 \\
\hline
\end{tabular}

Standard errors in parentheses 